\title{
Effects of Inhalation Exposure to Propylene Oxide on Respiratory Tract, Reproduction and Development in Rats
}

\author{
Hirokazu Okuda, Tetsuya Takeuchi, Hideki Senoh, Heihachiro Arito, Kasuke Nagano, \\ Seigo Yамамото and Taijiro Matsushima
}

Japan Bioassay Research Center, Japan Industrial Safety and Health Association, Japan

\begin{abstract}
Effects of Inhalation Exposure to Propylene Oxide on Respiratory Tract, Reproduction and Development in Rats: Hirokazu OKuDA, et al. Japan Bioassay Research Center, Japan Industrial Safety and Health AssociationNasal, respiratory, reproductive and developmental toxicities of propylene oxide (PO) were examined by exposing male and female Sprague-Dawley rats to $P O$ vapor by inhalation at a concentration of 0 (control), $125,250,500$ or $1,000 \mathrm{ppm}$ for $6 \mathrm{~h} / \mathrm{d}, 7 \mathrm{~d} / \mathrm{wk}$, during a 5- to 6-wk period, including premating, mating and postmating or gestation. The inhalation exposure to 1,000 ppm PO seriously affected parental survival, the upper and lower respiratory tract, male and female reproductive systems, motor function, and fetal survival and development, whereas the exposure to $500 \mathrm{ppm}$ or less primarily caused nasal lesions without any sign of reproductive or developmental toxicity. Because atrophy of the olfactory epithelium in the male rats exposed to $250 \mathrm{ppm}$ was the most sensitive endpoint for PO toxicity, the NOAEL was determined to be 125 ppm for the nasal endpoint. An additional inhalation experiment was carried out to further examine developmental toxicity by exposing pregnant rats to 0 , $125,250,500,750$ or 1,000 ppm PO during a 2 -wk period of gestation, Day 6 through Day 19. The 2-wk inhalation experiment revealed that reduced fetal body weights and delayed ossification occurred in association with significantly reduced body weights of the dams exposed to 750 and $1,000 \mathrm{ppm}$, whereas neither fetal death nor teratogenicity occurred at those two exposure levels. It was concluded that the developmental toxicity of fetal death was manifested at parentally toxic exposure levels above 500 ppm, a level which seriously affected parental survival, the upper and lower respiratory tracts and reproductive
\end{abstract}

Received Apr 28, 2006; Accepted Jul 31, 2006

Correspondence to: H. Okuda, Japan Bioassay Research Center, Japan Industrial Safety and Health Association, 2445 Hirasawa, Hadano, Kanagawa 257-0015, Japan

(e-mail: h-okuda@jisha.or.jp) system.

(J Occup Health 2006; 48: 462-473)

Key words: Propylene oxide, Rats, Developmental toxicity, Reproduction, Respiratory tract, Nasal cavity

Propylene oxide (PO) has been widely used as an intermediate for the industrial production of polyurethane foams and polyester fibers, and to a lesser extent, in the sterilization of medical equipment and as a fumigant for foodstuffs ${ }^{1)}$. Annual production of PO in 2000 was estimated to be 1,673,000 tons in the USA ${ }^{2)}$ and 353,000 tons in Japan ${ }^{3)}$. A total of 100,000 male workers and 317,000 female workers were occupationally exposed to PO in the USA between 1981 and 1983, according to the National Occupational Exposure Survey conducted by the National Institute for Occupational Safety and Health $(\mathrm{NIOSH})^{4}$. Excessive inhalation exposure of workers to PO vapor was reported to cause irritation of the eyes, respiratory tract and lung, and dermal contact with PO liquid caused irritation and necrosis of the skin ${ }^{5)}$. Experimental toxicology studies demonstrated that repeated inhalation exposure of rats to PO induced axonal degeneration of myelinated fibers in the central and peripheral nervous systems ${ }^{6}$, degenerative change and increased cell proliferation in the respiratory and olfactory epithelia of the nasal cavity ${ }^{7)}$, and degenerative, inflammatory and hyperplastic responses in the nasal mucosa, as well as nasal and mammary tumors ${ }^{8-11)}$. Omura et $a l .{ }^{12)}$ reported dose-dependent testicular toxicity in rats intraperitoneally administered PO at 23, 47 and $93 \mathrm{mg} / \mathrm{kg}$ for $3 \mathrm{~d} / \mathrm{wk}$ for 6 -wk and at $186 \mathrm{mg} / \mathrm{kg}$ for $3 \mathrm{~d} /$ wk for the first 2-wk and once a week for the next 4-wk. Hardin et al. ${ }^{13)}$ reported that inhalation exposure to $\mathrm{PO}$ at $300 \mathrm{ppm}$ for $7 \mathrm{~h} / \mathrm{d}$ for $5 \mathrm{~d}$ caused neither increased preimplantation loss nor reduced the number of living implants in the dominant lethal test using rats. They also reported no increased frequency of abnormal sperm in the sperm-head morphology test using mice. Three studies of experimental reproductive/developmental 
toxicology involving PO have been reported to date. Inhalation exposure of female rats to $500 \mathrm{ppm}$ PO for 3wk before mating and for GD 1 through 16 was reported to decrease the numbers of corpora lutea in the dams and increased the incidences of rib dysmorphology and reduced skeletal ossification in the fetuses ${ }^{14}$. No evidence of fetal malformation or variation except a sole variation of the seventh cervical vertebra was demonstrated in pregnant rats exposed by inhalation to $\mathrm{PO}$ at levels up to $500 \mathrm{ppm}$ for $6 \mathrm{~h} / \mathrm{d}$ from GD 6 through $15^{15)}$. Also, no adverse effects on reproductive function over two generations were evidenced by inhalation exposure of male and female rats to $\mathrm{PO}$ at levels up to $300 \mathrm{ppm}$ for 14-wk before mating, and during the mating, gestation and lactation periods, and subsequent inhalation exposure of selected male and female $F_{1}$ pups to the same levels of PO for 17-wk beginning from 5-wk of age until mating to produce the $\mathrm{F}_{2}$ litters $^{16)}$. Since a primary route of exposure of workers to PO is inhalation of its vapor, an occupational exposure limit (OEL) for PO has been established as 2 ppm Threshold Limit Value-Time Weighted Average (TLV-TWA) by the American Conference of Governmental Industrial Hygienists $(\mathrm{ACGIH})^{17)}$.

In animal toxicity studies available for OEL setting, it is important to determine the most sensitive, biologically significant and adverse effects among various facets of toxicities including reproductive toxicity in the parents and developmental toxicity in the offspring. This study was designed to assess the toxic characteristics of PO in rats and dose-response relationships for effective endpoints, including reproductive/developmental and systemic toxicities. For this purpose, overall evaluation of the PO toxicity was attempted by two inhalation experiments, with reference to the Organisation for Economic Co-operation and Development (OECD) Guideline for the Testing of Chemicals 422 (combined repeated dose toxicity study with the reproduction/ developmental toxicity screening test $)^{18)}$. The importance of nasal toxicity in relation to reproductive/developmental and systemic toxicities is presented here for overall evaluation of the toxic potency of PO.

\section{Materials and Methods}

This study was conducted in accordance with the OECD Principles of Good Laboratory Practice ${ }^{19}$. The animals were cared for in accordance with the Guide for the Care and Use of Laboratory Animals ${ }^{20)}$. This study was approved by the ethics committee of the Japan Bioassay Research Center.

\section{Animal}

Six-week-old male and female Crj:CD(SD)IGS rats were purchased from Charles River Japan, Inc. (Atsugi, Japan). After 1-wk of quarantine, the animals were acclimated to inhalation chambers made of stainless steel and glass of $1.11 \mathrm{~m}^{3}$ in volume, and equipped with an automatic watering system. After 1-wk of acclimation in the exposure chambers, they were weighed and divided into 5 groups of 10 animals per each sex by body weightstratified randomization. All animals were individually housed in stainless-steel wire mesh cages in the inhalation chambers during the exposure period. After 2-wk of exposure to $\mathrm{PO}$ or clean air, female rats were paired with males on a 1:1 basis within the same dose group every night, until copulation or for 2 -wk for evaluation of fertility. Every morning the females were checked for the presence of sperm or a plug in their vagina. The day that sperm or a plug in the vagina was detected was defined as gestation day (GD) 0 . After copulation, female and male rats were housed in the exposure chambers all day long, throughout the remainder of the exposure period. On GD 20, the pregnant females were moved out of the exposure chambers and housed for natural delivery in stainless-steel box cages provided with nesting materials (ALPHA-dri ${ }^{\mathrm{TM}}$, Shepherd Specialty Papers, Inc., MI, USA). The temperature, relative humidity, air flow rate and pressure in the exposure chambers were maintained constant in the range of $22 \pm 1^{\circ} \mathrm{C}, 55 \pm 5 \%$, $212 \mathrm{l} / \mathrm{min}$ and -5 to $-15 \mathrm{mmH}_{2} \mathrm{O}$, respectively. Fluorescent lighting was controlled automatically to give a 12-h light (08:00-20:00)/dark (20:00-08:00) cycle. Filtered, UV-irradiated tap water and commercial pellet diet (CRF-1, $\gamma$-irradiated with $30 \mathrm{KGy}$, Oriental Yeast Co., Tokyo, Japan) were given ad libitum.

\section{Chemical}

Reagent grade of PO (purity 100\%) was obtained from Wako Pure Chemical Industries, Ltd (Osaka, Japan). The PO used in this study was analyzed for its identity and purity by both infrared spectrometry and mass spectrometry and for its stability by gas chromatography. Neither decomposition products nor impurities were detected.

\section{Inhalation exposure to $P O$}

Inhalation exposure to $\mathrm{PO}$ vapor was performed, using the same method and technique as described in a previous study $^{21)}$. Airflow containing 0 (clean air), 125, 250, 500 or $1,000 \mathrm{ppm}(\mathrm{v} / \mathrm{v})$ of $\mathrm{PO}$ vapor as a target concentration was prepared. Chamber concentrations of PO were monitored by gas chromatography every 15 min during the daily $6 \mathrm{~h}$ exposure period and were kept constant at $125.3 \pm 0.8($ mean \pm SD), $250.5 \pm 1.2,500.4 \pm 2.3$ and $1,000.1 \pm 4.1 \mathrm{ppm}$. Groups of 10 males and 10 females each were exposed to clean air, and served as respective controls.

\section{Experimental schedule}

Female rats were exposed to PO for $6 \mathrm{~h} / \mathrm{d}$ for $7 \mathrm{~d} / \mathrm{wk}$ 
during the 2-wk premating period, during the mating period until copulation and during the gestation period, from GD 0 through 19. The number of PO exposure days of female rats ranged in total from 35 to 39 days, depending on the start of gestation. Male rats were exposed to PO for $6 \mathrm{~h} / \mathrm{d}$ for $7 \mathrm{~d} / \mathrm{wk}$ during the 6 -wk period, consisting of 2-wk premating, 2-wk mating and 2-wk postmating. Both sexes per group were exposed at the same time in a chamber, giving a total of five chambers for five groups.

\section{Examinations and assessments}

Animals were observed daily for clinical signs and mortality. Body weights were measured once a week throughout the whole study period. Pregnant females were allowed to deliver naturally, and the day of parturition was defined as postnatal day (PND) 0. Pups were examined for sex, mortality and external malformations on PND 0 and for viability on PND 0 through 4. Pup weights were measured per sex per litter on PND 0 and 4. Dams and pups were sacrificed by diethylether anesthesia on PND 4, and non-delivered dams were sacrificed on the day corresponding to GD 26. The dams were examined for numbers of corpora lutea on ovaries and implantations in uteri. Males were sacrificed by diethyl ether anesthesia after the 6-wk exposure period. All the males and females underwent complete necropsy. Sperm taken from the caudal epididymis was examined using a sperm analyzer (TOX IVOS, Hamilton Thorne Biosciences, Inc., MA, USA) for sperm motility and count. Serum concentrations of luteinizing hormone $(\mathrm{LH})$, follicle stimulating hormone (FSH) and testosterone in male rats were determined, using the EIA system (Amersham Pharmacia Biotech, Inc., Uppsala, Sweden) and the Active ${ }^{\mathrm{TM}}$ testosterone EIS system (Diagnostic Systems Laboratories, Inc., TX, USA). Organs were removed, weighed and examined for macroscopic lesions. For histopathological examination, the testis and epididymis were fixed in Bouin's solution, and the other organs were fixed in neutral buffered $10 \%$ formalin. Pretreatment of the nasal cavity for histopathological examination and the method for trimming 3 frontal sections at the levels of the posterior edge of the upper incisor teeth (Level 1), the incisive papilla (Level 2) and the anterior edge of the upper molar teeth (Level 3) were described in a paper by Aiso et al. ${ }^{22}$. Severity grades of nasal lesions were scored on the basis of affected area; Grade 1 for less than $10 \%$, Grade 2 for 10 to $40 \%$, and Grade 3 for more than $40 \%$ of the total area of either respiratory or olfactory epithelial region. Tissue sections of $5 \mu \mathrm{m}$ in thickness were prepared and stained with hematoxylin and eosin ( $\mathrm{H} \& \mathrm{E})$.

\section{Additional inhalation experiment for developmental toxicity}

For further examination of developmental toxicity, an inhalation experiment was carried out by exposing 6 groups of 5 pregnant rats each, which had been mated in the animal room and then moved to the inhalation chambers on GD 0 , to PO vapor at $0,125,250,500,750$ or $1,000 \mathrm{ppm}$ for $6 \mathrm{~h} / \mathrm{d}$ for 14 consecutive gestation days (GD 6 through 19). Addition of 750 ppm to the exposure regimen was based on the results of the main inhalation experiment that no live pups were born in the group exposed to 1,000 ppm PO, whereas no developmental effect was induced in the pups of the group exposed to $500 \mathrm{ppm}$ PO. The exposure of pregnant females to 750 ppm PO was presumed to correspond to a critical concentration for induction of fetal abnormalities. The pregnant rats were delivered by Cesarean section on GD 20. The numbers of dead and live fetuses were recorded. Live fetuses were weighed, sexed, and examined for external, skeletal and visceral anomalies, using the methods described in our previous papers ${ }^{23,24)}$.

\section{Statistical analyses}

Copulation and fertility indices, number of pregnant females that delivered live pups, and histopathological findings were analyzed by the Chi-square test between the control and the PO-exposed groups. Other parameters were analyzed by Dunnett's test. At first, Bartlett's test was used to test for homogeneity of variance. When the variance was homogeneous, one-way ANOVA was used. When the variance was not homogeneous, Kruskal-Wallis rank sum test was performed, by arranging all data for the control and exposure groups in descending order. Statistical differences in the means and the rank means among the groups were analyzed by Dunnett's multiple comparison test, and the same multiple comparison test by rank, respectively. A two-sided analysis with a $p$ value of 0.05 was performed.

\section{Results}

Three males exposed to 1,000 ppm PO were found in a moribund state in the final week of the postmating period. Three pregnant females exposed to $1,000 \mathrm{ppm}$ PO were found in a moribund state during the middle of the gestation period, and one non-pregnant female exposed to $1,000 \mathrm{ppm}$ died in the 5 th wk of repeated exposure. The cause of their deaths was attributed to respiratory failure on the diagnostic basis of lung inflammation of severe grade, revealed in the histopathological examination, reddish lung noted by macroscopic examination at necropsy, and irregular respiration followed by deep and slow breathing before their death, on gross observation. Irregular respiration was observed in 6 males and 3 females exposed to 1,000 ppm. Ataxic gait occurred in 7 males and 4 females exposed to $1,000 \mathrm{ppm}$, indicating impairment of motor function. Body weight was decreased in the males 


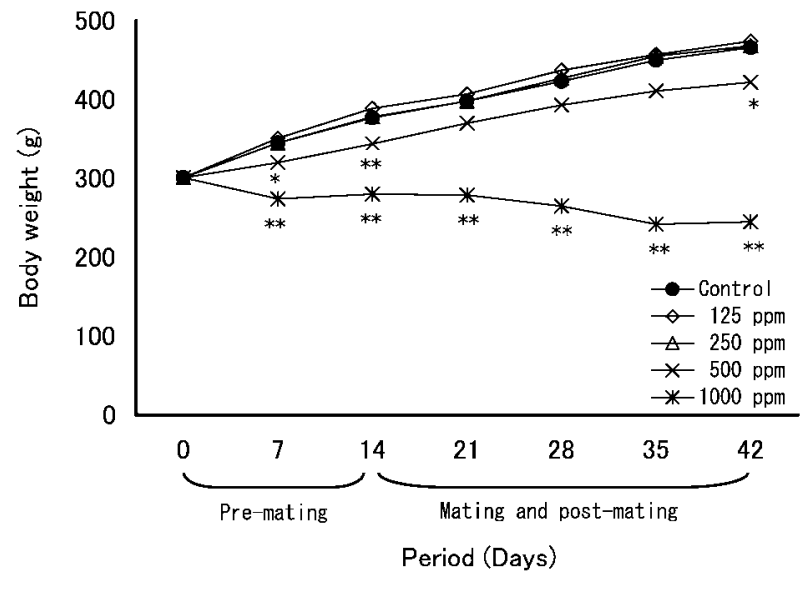

Fig. 1. Time-course changes in body weights of male rats exposed to $\mathrm{PO}$ at a level of 0 (control), 125, 250, 500 or 1,000 ppm for $6 \mathrm{~h} / \mathrm{d}, 7 \mathrm{~d} / \mathrm{wk}$ for 6 -wk, including the pre-mating, mating and post-mating periods. Each symbol represents mean body weight. Single and double asterisks indicate statistically significant difference as compared with control at $p<0.05$ and $p<0.01$ by Dunnett's test, respectively.

exposed to both 500 and 1,000 ppm on the 7th day of the repeated exposure and later, and in the females exposed to $1,000 \mathrm{ppm}$ during the premating and gestation periods (Figs. 1 and 2).

\section{Respiratory tract toxicity}

In the histopathological examination (Table 1), lesions in PO-exposed male and female rats occurred in the upper and lower respiratory tract, particularly in the respiratory and olfactory mucosa of the nasal cavity. In the anterior portion (Level 1) of the nasal cavity, regeneration of respiratory epithelium which was replaced with the squamous epithelium or which migrated to the cuboidal epithelium was observed in groups of both sexes exposed to $1,000 \mathrm{ppm}$. In the olfactory epithelium, incidences and severities of necrosis, atrophy and regeneration were increased with an increase in exposure concentration. Necrosis was characterized by pyknosis or karyorrhexis of the nuclei and exfoliation of the epithelial cells into the lumen of the nasal cavity. Atrophy of the olfactory epithelium was characterized by decreased epithelial thickness and decreased numbers of olfactory sensory cells (Fig. 3). Atrophy of both the nerve bundles and olfactory glands within the lamina propria was also evident. The olfactory epithelial atrophy occurred only at the dorsal meatus of middle portion (Level 2) of the nasal cavity in the males exposed to $250 \mathrm{ppm}$, and its average grade of severity was 1.0 , corresponding to the slight grade. The affected area extended to the olfactory epithelium lining the dorsal meatus of the posterior portion (Level 3) in groups of both sexes exposed to 500

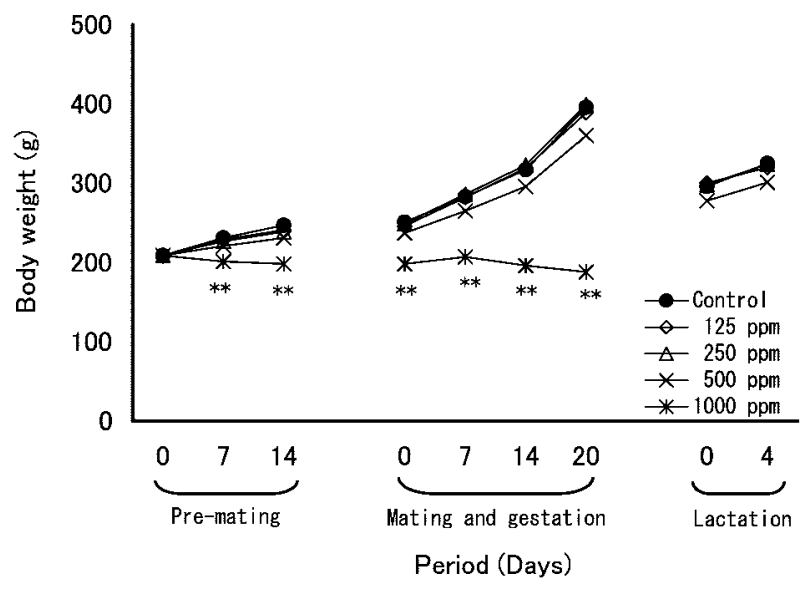

Fig. 2. Time-course changes in body weights of female rats exposed to $\mathrm{PO}$ at a level of 0 (control), 125, 250, 500 or $1,000 \mathrm{ppm}$ for $6 \mathrm{~h} / \mathrm{d}, 7 \mathrm{~d} / \mathrm{wk}$ for 5 - to 6 -wk, including the pre-mating, mating and gestation periods. Each symbol represents mean body weight. Double asterisks indicate statistically significant difference as compared with control at $p<0.01$ by Dunnett's test.

ppm, and at the entire area of the posterior portion (Level 3 ) in groups of both sexes exposed to 1,000 ppm. The averaged severity grades of the olfactory epithelial atrophy in the males and females of the 1,000 ppm exposure group were 3.0 and 2.7, respectively, both of which corresponded to the marked grade. Regeneration of the olfactory epithelium was characterized by either respiratory metaplasia or epithelial disarrangement. Inflammation infiltrated primarily by neutrophils was observed throughout the entire area of the respiratory and olfactory mucosa in groups of both sexes exposed to 1,000 ppm. Regeneration of laryngeal epithelium characterized by squamous metaplasia was observed in groups of both sexes exposed to $1,000 \mathrm{ppm}$.

In the lung, inflammation and alveolar macrophage aggregate occurred in groups of both sexes exposed to $1,000 \mathrm{ppm}$, the former lesion appearing at $500 \mathrm{ppm}$. Inflammation infiltrated by neutrophils was observed throughout the entire area from the bronchus to alveolus. Alveolar macrophage aggregate was characterized by accumulation of foamy cells in the alveolus around the terminal bronchiole. The histopathologically observed lesions in the upper and lower respiratory tract were diagnosed according to the Guide for Toxicologic Pathology by Renne et al. ${ }^{25}$.

\section{Reproductive toxicity}

Table 2 shows effects of PO on male reproduction, as well as on copulation and fertility of the female rats that had mated with the males exposed to the same levels of PO. Six-wk inhalation exposure of male rats to 1,000 
Table 1. Histopathological changes in the respiratory tract of male and female rats exposed to PO at 4 different concentrations or clean air as a control

\begin{tabular}{|c|c|c|c|c|c|c|}
\hline $\mathrm{ppm}^{1)}$ & 0 & 125 & 250 & 500 & & 000 \\
\hline$<$ Male $>$ & $<10>$ & $<10>$ & $<10>$ & $<10>$ & & $10>$ \\
\hline \multicolumn{7}{|l|}{ Nasal cavity } \\
\hline \multicolumn{7}{|l|}{ Respiratory epithelium } \\
\hline Regeneration & 0 & 0 & 0 & 0 & 10 & $(1.0)^{\# \#}$ \\
\hline \multicolumn{7}{|l|}{ Olfactory epithelium } \\
\hline Necrosis & 0 & 0 & 0 & $2(1.0)$ & 10 & $(1.2)^{\# \#}$ \\
\hline Atrophy & 0 & 0 & $5(1.0)^{\#}$ & $10 \quad(1.2)^{\# \#}$ & 10 & $(3.0)^{\# \#}$ \\
\hline Regeneration & 0 & 0 & 0 & $3(1.0)$ & 10 & $(1.2)^{\# \#}$ \\
\hline Inflammation & 0 & 0 & 0 & $1(1.0)$ & 10 & $(2.0)^{\# \#}$ \\
\hline \multicolumn{7}{|l|}{ Larynx } \\
\hline Regeneration & 0 & 0 & 0 & 0 & 10 & $(1.0)^{\# \#}$ \\
\hline \multicolumn{7}{|l|}{ Lung } \\
\hline Inflammation & 0 & 0 & 0 & $3(1.0)$ & 8 & $(2.0)^{\# \#}$ \\
\hline $\begin{array}{l}\text { Alveolar macrophage aggregate: } \\
\text { alveolus of peri-terminal bronchiole }\end{array}$ & 0 & 0 & 0 & 0 & 8 & $(2.5)^{\# \#}$ \\
\hline$<$ Female $>$ & $<10>$ & $<10>$ & $<10>$ & $<10>$ & & $10>$ \\
\hline \multicolumn{7}{|l|}{ Nasal cavit } \\
\hline \multicolumn{7}{|l|}{ Respiratory epithelium } \\
\hline Regeneration & 0 & 0 & 0 & 0 & 7 & $(1.4)^{\#}$ \\
\hline \multicolumn{7}{|l|}{ Olfactory epithelium } \\
\hline Necrosis & 0 & 0 & 0 & 0 & 8 & $(1.3)^{\# \#}$ \\
\hline Atrophy & 0 & 0 & 0 & $9(1.0)^{\# \#}$ & 10 & $(2.7)^{\# \#}$ \\
\hline Regeneration & 0 & 0 & 0 & $4 \quad(1.0)$ & 6 & $(1.3)^{\#}$ \\
\hline Inflammation & 0 & 0 & 0 & 0 & 8 & $(2.0)^{\# \#}$ \\
\hline \multicolumn{7}{|l|}{ Larynx } \\
\hline Regeneration & 0 & 0 & 0 & 0 & 4 & $(1.0)$ \\
\hline \multicolumn{7}{|l|}{ Lung } \\
\hline Inflammation & 0 & 0 & 0 & $2(1.0)$ & 10 & $(2.2)^{\# \#}$ \\
\hline $\begin{array}{l}\text { Alveolar macrophage aggregate: } \\
\text { alveolus of peri-terminal bronchiole }\end{array}$ & 0 & 0 & 0 & $1 \quad(2.0)$ & 6 & $(1.8)^{\#}$ \\
\hline
\end{tabular}

Values in angular brackets indicate the number of animals examined. Values in round bracket indicate the average of the severity grade index of the lesions in the affected animals. The averages of the severity grade index were calculated with the following equation: [ $\Sigma$ (grade $\times$ number of animals with grade) /number of animals examined. Grade: 1 , slight; 2 , moderate; 3 , marked]

\# and \#\#: Significantly different from control group at $p<0.05$ and $p<0.01$ by Chi-Square test, respectively. ${ }^{1)}$ : Animals were exposed to PO during the 6-wk (male) or 5- to 6-wk (female) periods including premating, mating and postmating or gestation.

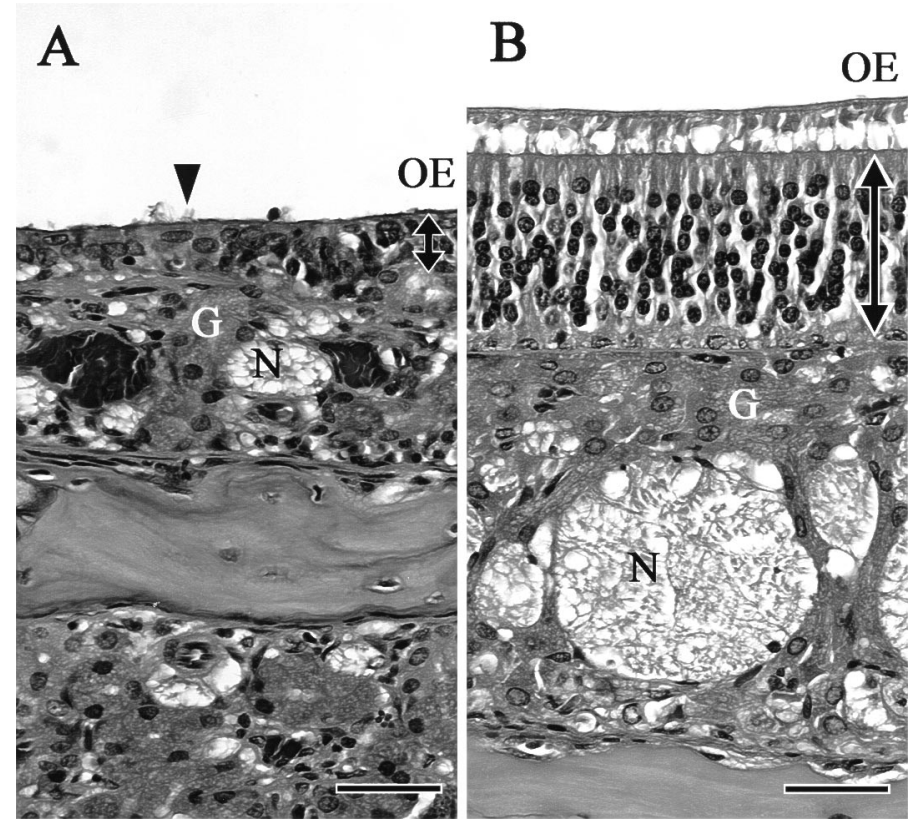

Fig. 3. A: Atrophy of the olfactory epithelium in a male rat exposed to $1,000 \mathrm{ppm}$ PO for 6-wk. Decreases in epithelial thickness and number of olfactory sensory cells, respiratory metaplasia (arrow head), and atrophy of both the nerve bundles and the olfactory glands within the lamina propria are noted. B: Normal olfactory epithelium of a male rat exposed to clean air as a control for $6 \mathrm{wk}$. OE (double-headed arrows): Olfactory epithelium. $\mathrm{N}$ : Nerve bundle. G: Olfactory gland. Bar indicates $50 \mu \mathrm{m}$. 
Table 2. Reproductive toxicity of male and female rats exposed to PO at 4 different concentrations or clean air as a control

\begin{tabular}{|c|c|c|c|c|c|}
\hline $\mathrm{ppm}^{1)}$ & 0 & 125 & 250 & 500 & 1,000 \\
\hline \multicolumn{6}{|l|}{$<$ Male $>$} \\
\hline \multicolumn{6}{|l|}{ Histopathology } \\
\hline Testis & $<10>$ & $<10>$ & $<10>$ & $<10>$ & $<10>$ \\
\hline Germ cell necrosis & 0 & 0 & 0 & 0 & $6^{\#}$ \\
\hline Epididymis & $<10>$ & $<10>$ & $<10>$ & $<10>$ & $<10>$ \\
\hline Decreased: sperma & 0 & 1 & 0 & 0 & $6^{\#}$ \\
\hline Debris of spermatic elements & 0 & 1 & 0 & 0 & $6^{\#}$ \\
\hline Organ weight & $<10>$ & $<10>$ & $<10>$ & $<10>$ & $<7>$ \\
\hline \multirow[t]{2}{*}{ Testis } & $3.21 \pm 0.22$ & $2.95 \pm 0.75$ & $3.15 \pm 0.35$ & $3.19 \pm 0.16$ & $2.29 \pm 0.42 * *$ \\
\hline & $0.74 \pm 0.06$ & $0.66 \pm 0.16$ & $0.73 \pm 0.06$ & $0.82 \pm 0.04 *$ & $1.03 \pm 0.15^{* *}$ \\
\hline \multirow[t]{2}{*}{ Seminal vesicle } & $1.46 \pm 0.24$ & $1.55 \pm 0.29$ & $1.48 \pm 0.23$ & $1.41 \pm 0.19$ & $0.35 \pm 0.17 *$ \\
\hline & $0.34 \pm 0.06$ & $0.35 \pm 0.06$ & $0.34 \pm 0.06$ & $0.36 \pm 0.06$ & $0.15 \pm 0.06^{* *}$ \\
\hline \multirow[t]{2}{*}{ Prostate } & $1.31 \pm 0.24$ & $1.49 \pm 0.34$ & $1.47 \pm 0.19$ & $1.29 \pm 0.15$ & $0.50 \pm 0.12 * *$ \\
\hline & $0.30 \pm 0.04$ & $0.34 \pm 0.07$ & $0.34 \pm 0.05$ & $0.33 \pm 0.05$ & $0.23 \pm 0.05^{*}$ \\
\hline Concentration of hormones & $<10>$ & $<10>$ & $<10>$ & $<10>$ & $<7>$ \\
\hline Testis $\quad(\mathrm{g})$ & $3.21 \pm 0.22$ & $2.95 \pm 0.75$ & $3.15 \pm 0.35$ & $3.19 \pm 0.16$ & $2.29 \pm 0.42 * *$ \\
\hline LH (ng/mL) & $3.3 \pm 0.5$ & $3.5 \pm 0.5$ & $3.4 \pm 0.5$ & $3.7 \pm 0.6$ & $4.4 \pm 0.8 * *$ \\
\hline FSH (ng/mL) & $48.6 \pm 9.6$ & $42.3 \pm 14.3$ & $44.1 \pm 14.4$ & $47.9 \pm 17.0$ & $78.5 \pm 47.0 * *$ \\
\hline Testosterone $(\mathrm{ng} / \mathrm{mL})$ & $3.5 \pm 4.2$ & $1.8 \pm 1.6$ & $2.5 \pm 2.9$ & $3.2 \pm 3.5$ & $0.6 \pm 0.2 * *$ \\
\hline \multicolumn{6}{|l|}{ Sperm examinations } \\
\hline Concentration of hormones & $<10>$ & $<10>$ & $<10>$ & $<10>$ & $<7>$ \\
\hline \multirow[t]{2}{*}{ Motion: motile (\%) } & $<10>$ & $<10>$ & $<10>$ & $<10>$ & $<4>4)$ \\
\hline & $88 \pm 4$ & $85 \pm 5$ & $88 \pm 6$ & $83 \pm 8$ & $55 \pm 13 * *$ \\
\hline \multirow[t]{2}{*}{ Count: No. of sperm (million/g) } & $<10>$ & $<10>$ & $<10>$ & $<10>$ & $<7>$ \\
\hline & $694.3 \pm 96.3$ & $646.5 \pm 232.7$ & $731.7 \pm 171.6$ & $734.0 \pm 108.2$ & $239.9 \pm 169.0^{* *}$ \\
\hline \multicolumn{6}{|l|}{$<$ Female $>$} \\
\hline No. of mated pairs & 10 & 10 & 10 & 10 & 10 \\
\hline No. of copulated pairs & 10 & 10 & 10 & 10 & 9 \\
\hline Copulation index $(\%)^{2)}$ & 100 & 100 & 100 & 100 & 90 \\
\hline No. of pregnant females & 10 & 9 & 10 & 10 & 7 \\
\hline Fertility index $(\%)^{3)}$ & 100 & 90 & 100 & 100 & 78 \\
\hline Pairing days until copulation & $2.7 \pm 1.1$ & $2.6 \pm 1.1$ & $3.3 \pm 1.1$ & $2.3 \pm 1.1$ & $3.1 \pm 1.5$ \\
\hline
\end{tabular}

Values are expressed as mean \pm S.D. Values in angular brackets indicate the number of animals examined. * and ** : Significantly different from control group at $p<0.05$ and $\mathrm{p}<0.01$ by Dunnett's test, respectively. \#: Significantly different from control group at $p<0.05$ by Chi-Square test. 1): Animals were exposed to PO during the 6 -wk (male) or 5 - to 6 -wk (female) periods including premating, mating and postmating or gestation. ${ }^{2}$ : Copulation index $=($ No. of copulated pairs $/$ No. of mated pairs $) \times 100$. 3): Fertility index $=($ No. of pregnant females $/$ No. of copulated pairs $) \times 100$. ${ }^{4}$ : Three males were not examined, because moving sperms were not observed in the sperm culture.

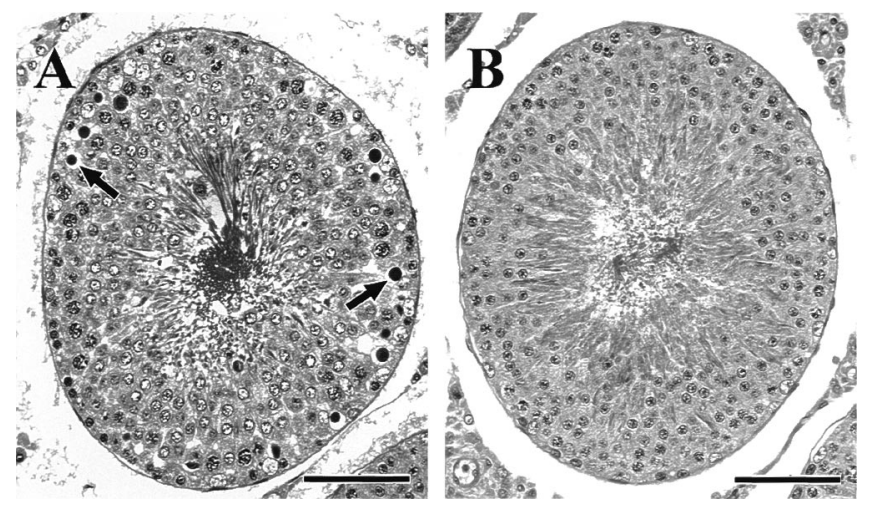

Fig. 4. A: Germ cell necrosis in the seminiferous tubule of testis in a male rat exposed to 1,000 ppm PO for 6-wk. Necrosis of the primary spermatocytes is indicated (arrows). B: Normal seminiferous tubule of testis in a male rat exposed to clean air as a control for 6wk. Bar indicates $100 \mu \mathrm{m}$. 
Table 3. Developmental effects on pups whose parents were exposed to PO at 4 different concentrations or clean air as a control

\begin{tabular}{|c|c|c|c|c|c|}
\hline & $\mathrm{ppm}^{1)}$ & 125 & 250 & 500 & 1,000 \\
\hline No. of pregnant females & 10 & 9 & 10 & 10 & 7 \\
\hline $\begin{array}{l}\text { No. of pregnant females } \\
\text { delivered pups }\end{array}$ & 10 & 9 & 10 & 10 & $0^{\# \#}$ \\
\hline Gestation length (day) & $22.1 \pm 0.3$ & $22.0 \pm 0.0$ & $22.1 \pm 0.3$ & $22.2 \pm 0.4$ & - \\
\hline No. of corpora lutea & $16.0 \pm 1.9$ & $17.1 \pm 2.3$ & $17.5 \pm 1.8$ & $16.8 \pm 2.0$ & $16.0 \pm 2.5$ \\
\hline No. of implantations & $14.1 \pm 3.9$ & $15.6 \pm 2.5$ & $15.6 \pm 1.6$ & $14.4 \pm 2.1$ & $12.1 \pm 2.6$ \\
\hline Implantation index $(\%)^{2)}$ & $87.2 \pm 20.9$ & $91.0 \pm 8.0$ & $90.0 \pm 11.9$ & $86.1 \pm 11.7$ & $78.4 \pm 22.8$ \\
\hline \multicolumn{6}{|l|}{ PND 0} \\
\hline No. of pups born & $13.8 \pm 3.9$ & $13.7 \pm 3.2$ & $14.9 \pm 1.9$ & $12.7 \pm 2.3$ & $0 * *$ \\
\hline Delivery index $(\%)^{3)}$ & $98.0 \pm 4.5$ & $87.1 \pm 8.9$ & $95.4 \pm 5.4$ & $88.3 \pm 10.4$ & $0 * *$ \\
\hline No. of live pups & $13.5 \pm 3.9$ & $13.4 \pm 3.0$ & $14.9 \pm 1.9$ & $12.5 \pm 2.8$ & - \\
\hline \multicolumn{6}{|l|}{ Pups weight (g) } \\
\hline Males & $6.7 \pm 0.4$ & $6.6 \pm 0.7$ & $6.4 \pm 0.3$ & $6.7 \pm 0.4$ & - \\
\hline Females & $6.2 \pm 0.5$ & $6.2 \pm 0.6$ & $6.0 \pm 0.3$ & $6.4 \pm 0.5$ & - \\
\hline Sex ratio ${ }^{4}$ & $0.4 \pm 0.1$ & $0.5 \pm 0.2$ & $0.5 \pm 0.2$ & $0.6 \pm 0.1$ & - \\
\hline \multicolumn{6}{|l|}{ PND 4} \\
\hline No. of live pups & $13.1 \pm 3.7$ & $13.1 \pm 2.4$ & $14.7 \pm 1.8$ & $12.5 \pm 2.8$ & - \\
\hline Viability index $(\%)^{5)}$ & $97.4 \pm 4.4$ & $98.2 \pm 5.3$ & $98.8 \pm 4.0$ & $100.0 \pm 0.0$ & - \\
\hline \multicolumn{6}{|l|}{ Pups weight (g) } \\
\hline Males & $10.8 \pm 1.1$ & $10.4 \pm 1.7$ & $10.3 \pm 0.9$ & $11.0 \pm 0.8$ & - \\
\hline Females & $10.2 \pm 1.2$ & $10.1 \pm 1.6$ & $9.8 \pm 0.9$ & $10.5 \pm 1.0$ & - \\
\hline
\end{tabular}

Values are expressed as mean \pm S.D. \#*: Significantly different from control group at $p<0.01$ by Chi-Square test. **: Significantly different from control group at $p<0.01$ by Dunnett's test. ${ }^{1)}$ : Animals were exposed to PO during the 6-wk (male) or 5- to 6-wk (female) periods including premating, mating and postmating or gestation. ${ }^{2}$ ): Implantation index $=($ No. of implantations / No. of corpora lutea $) \times 100 .{ }^{3}$ ): Delivery index $=($ No. of pups born $/$ No. of implantations $\left.) \times 100 .{ }^{4}\right)$ : Sex ratio $=$ No. of live male pups on PND 0 / No. of live pups on PND 0. 5): Viability index $=($ No. of live pups on PND 4 / No. of live pups on PND 0$) \times 100$.

ppm PO significantly increased the incidence of germ cell necrosis in the seminiferous tubule, incidences of decreased sperm and debris of spermatic elements in the epididymis, and significantly decreased the absolute and relative weights of seminal vesicle and prostate and both motility and number of sperm. Absolute testis weight was statistically decreased in males of the 1,000 ppm exposure group, while relative testis weight was statistically increased in males exposed to 500 and 1,000 ppm. Because the body weights of males in the 1,000 ppm exposure group were significantly decreased, the statistically significant changes in the relative and absolute testis weights were considered not to reflect a biologically significant change, suggesting no effect of PO on testis weight. Germ cell necrosis (Fig. 4) was mild and characterized by nuclear and cytoplasmic hyperchromasia of primary spermatocytes, but those changes occurred without any apparent histopathological change in Sertoli or Leydig cells. Notably, a significant decrease in the serum level of testosterone with a concomitant increase in LH and FSH occurred in males exposed to $1,000 \mathrm{ppm}$.
Copulation and fertility of males and females exposed to PO were characterized by an absence of copulation in one out of the ten parental pairs exposed to $1,000 \mathrm{ppm}$ and by non-pregnancy in two out of the nine copulating pairs exposed to $1,000 \mathrm{ppm}$, resulting in decreased copulation and fertility indices and a decreased number of pregnant females, although these decreased values were not statistically different from their respective controls.

\section{Developmental toxicity}

Developmental effects on pups from the parents exposed to PO during the 5- to 6 -wk period are summarized in Table 3. Although there was no statistically significant difference in the number of corpora lutea between any of the PO-exposed groups and the control, inhalation exposure to $1,000 \mathrm{ppm}$ PO tended to decrease the number of implantations and the implantation index. Notably, no pup was born to any of the seven dams in the 1,000 ppm exposure group that had mated with the males exposed to PO at the same level. However, except for the 1,000 ppm exposure group, there were no significant differences in the numbers of 
Table 4. Developmental toxicity of fetuses from the dams exposed to PO at 5 different concentrations or clean air as a control during the 2-wk period of GD 6 through 19

\begin{tabular}{|c|c|c|c|c|c|c|}
\hline ppm & 0 & 125 & 250 & 500 & 750 & 1,000 \\
\hline No. of dams examined & 5 & 5 & 5 & 5 & 5 & 5 \\
\hline \multicolumn{7}{|l|}{ Maternal body weight } \\
\hline GD 6 & $267 \pm 14$ & $262 \pm 13$ & $266 \pm 14$ & $261 \pm 8$ & $267 \pm 13$ & $263 \pm 15$ \\
\hline GD 13 & $289 \pm 13$ & $283 \pm 13$ & $286 \pm 15$ & $274 \pm 13$ & $262 \pm 17 *$ & $258 \pm 11^{*}$ \\
\hline GD 20 & $364 \pm 21$ & $362 \pm 17$ & $368 \pm 19$ & $335 \pm 24$ & $299 \pm 22 * *$ & $290 \pm 12^{* *}$ \\
\hline Implantation loss (\%) & $5.6 \pm 6.3$ & $6.6 \pm 7.7$ & $3.7 \pm 5.4$ & $6.2 \pm 8.6$ & $5.1 \pm 2.9$ & $3.8 \pm 3.5$ \\
\hline No. of live fetuses & $13.8 \pm 2.2$ & $14.0 \pm 1.6$ & $15.4 \pm 2.1$ & $14.6 \pm 1.1$ & $15.0 \pm 1.4$ & $14.2 \pm 1.3$ \\
\hline Fetal body weights (g) & $<69>$ & $<70>$ & $<77>$ & $<73>$ & $<75>$ & $<71>$ \\
\hline Males & $3.45 \pm 0.38$ & $3.72 \pm 0.17$ & $3.50 \pm 0.17$ & $3.14 \pm 0.23$ & $2.75 \pm 0.44^{*}$ & $2.62 \pm 0.50 * *$ \\
\hline Females & $3.41 \pm 0.27$ & $3.52 \pm 0.12$ & $3.35 \pm 0.14$ & $3.01 \pm 0.23$ & $2.59 \pm 0.40^{* *}$ & $2.49 \pm 0.49 * *$ \\
\hline Morphological observations & $<69>$ & $<70>$ & $<77>$ & $<73>$ & $<75>$ & $<71>$ \\
\hline$<$ Skeletal observation $>$ & $<36>$ & $<36>$ & $<40>$ & $<38>$ & $<38>$ & $<37>$ \\
\hline Malformations (\%) & 0 & 0 & 0 & 0 & 0 & 0 \\
\hline Variations $(\%)^{1)}$ & $2.5 \pm 5.6$ & $10.4 \pm 10.6$ & $10.4 \pm 10.6$ & $5.7 \pm 7.8$ & $2.5 \pm 5.6$ & $10.4 \pm 16.4$ \\
\hline $\begin{array}{l}\text { No. of ossified sacral-caudal } \\
\text { vertebrae }\end{array}$ & $7.6 \pm 0.6$ & $7.5 \pm 0.2$ & $7.4 \pm 0.5$ & $7.2 \pm 0.3$ & $6.1 \pm 0.8 * *$ & $5.6 \pm 1.3^{* *}$ \\
\hline$<$ Visceral observation $>$ & $<33>$ & $<34>$ & $<37>$ & $<35>$ & $<37>$ & $<34>$ \\
\hline Malformations (\%) & 0 & 0 & 0 & 0 & 0 & 0 \\
\hline Variations $(\%)^{2)}$ & $9.7 \pm 13.6$ & $9.5 \pm 14.7$ & $8.6 \pm 12.8$ & $5.7 \pm 12.8$ & $7.9 \pm 11.4$ & $8.6 \pm 19.2$ \\
\hline
\end{tabular}

Values are expressed as mean \pm S.D. Values in angular brackets indicate the number of fetuses examined. * and ** : Significantly different from control group at $p<0.05$ and $p<0.01$ by Dunnett's test, respectively. ${ }^{1)}$ : including short supernumerary rib, cervical rib, dumbbell ossification of thoracic centrum and bipartite ossification of thoracic centrum. ${ }^{2)}$ : including persistent left umbilical artery, supernumerary coronary ostium and thymic remnant in neck.

pups born and live pups on PND 0, body weights and sex ratio of male and female pups, or in the number of live pups and body weights on PND 4 between any of the PO-exposed groups and the respective control. No external malformation was detected in any pup from the parent groups exposed to PO.

The developmental effects on intrauterine fetuses from the dams exposed to PO only during the 2-wk period from GD 6 through 19 are summarized in Table 4. Notably, there were no significant differences in the number of live fetuses or implantation loss between any of the PO-exposed groups and the respective control. Body weights of male and female fetuses from dams exposed to both 750 and 1,000 ppm PO were significantly reduced, compared with the respective controls. The numbers of ossified sacral-caudal vertebrae were significantly decreased in the fetuses from dams exposed to both 750 and 1,000 ppm PO, compared with the control. On the other hand, there were no differences in incidences of fetal malformations or variations between any of the PO-exposed dams and the control. Body weights of dams in the 750 and 1,000 ppm exposure groups were significantly reduced on GD 13 and 20, compared with the respective controls.

\section{Discussion}

In this study, $6 \mathrm{~h} / \mathrm{d}$ inhalation exposure of male and female rats to $1,000 \mathrm{ppm}$ PO during a 5- to 6-wk period including premating, mating and postmating or gestation caused the death of 3 males and 4 females from respiratory failure, significantly decreased body weights, and seriously affected male and female reproductive systems, and their upper and lower respiratory tracts and motor functions. The affected male reproductive system was characterized by both mild germ cell necrosis in the seminiferous tubule and a significant decrease in the serum level of testosterone, with a concomitant increase in LH and FSH, without any apparent histopathological change in either Sertoli or Leydig cells or any change in testicular weight, and by significant decreases in motility and sperm counts and in weights of seminal vesicle and prostate.

At least two different, underlying mechanisms are likely to be involved in the PO-induced impairment of spermatogenesis. The first mechanism might involve alkylation of DNA and protein of germ cells by PO, resulting in germ cell necrosis. $\mathrm{PO}$ has been reported to bind to DNA and its components in aqueous solution ${ }^{26)}$ and to form PO-DNA adducts in the white blood cells of 
workers exposed to $\mathrm{PO}^{27)}$, and inhalation exposure of male mice to ethylene oxide, an alkylating agent like PO, was reported to alkylate DNA and protein of germ cells ${ }^{28)}$. A second, possibility is that altered biosynthesis and regulation of the sex hormones might be involved in the underlying mechanism, as evidenced by the significantly decreased serum level of testosterone, with concomitantly increased levels of LH and FSH in the male rats exposed to $1,000 \mathrm{ppm} \mathrm{PO}$, since testosterone is known to influence spermatogenesis through regulation of the anterior pituitary-testicular axis ${ }^{29,30}$. The obvious manifestation of PO-induced testicular toxicity found in this inhalation study can be contrasted with the findings of Omura et $a l .^{12)}$ who found that repeated intraperitoneal administration of PO to male rats induced decreased testicular and epididymal weights, decreased sperm counts and increased rates of sperm with morphological abnormalities, without any significant change in serum testosterone or histopathology of Leydig cells. There were similarities in the reduced sperm count and no apparent histopathological change in Leydig cells between the present inhalation study and the study of Omura et al. by intraperitoneal administration ${ }^{12)}$. However, the principal differences between these two studies are that germ cell necrosis, decreased weight of seminal vesicle and prostate and significantly decreased serum level of testosterone with concomitantly increased levels of LH and FSH were found only in the present inhalation study. These differences might be attributable to differences in the route of PO administration (i.e., inhalation exposure vs. intraperitoneal injection) and the number of repeated administrations and the repetition interval (i.e., $6 \mathrm{~h} / \mathrm{d}, 7 \mathrm{~d} / \mathrm{wk}$ for 6 -wk for the inhalation exposure to $125,250,500$ and 1,000 ppm versus $3 \mathrm{~d} / \mathrm{wk}$ for 6-wk for 23,47 and $93 \mathrm{mg} / \mathrm{kg} / \mathrm{d}$, and $3 \mathrm{~d} / \mathrm{wk}$ for the first 2-wk and once a week for next 4-wk for $186 \mathrm{mg} / \mathrm{kg} /$ d) between the present study and that of Omura et al. ${ }^{12}$. However, no apparent difference in the daily amount of PO administered was found between the two studies, because the intraperitoneal doses of 23, 47, 93 and 186 $\mathrm{mg} / \mathrm{kg} / \mathrm{d}$ in the study of Omura et al. were roughly the same order as the estimated amounts of body uptake of $60,120,360$ or $480 \mathrm{mg} / \mathrm{kg} / \mathrm{d}$ in the present study, which were arrived at by assuming a $561 \mathrm{ml} / \mathrm{min} / \mathrm{kg}$ body weight as the minute volume ${ }^{31)}$ and $100 \%$ for the lung absorption rate of $\mathrm{PO}$, for male rats inhaling $125,250,500$ or 1,000 ppm PO vapor for $6 \mathrm{~h} / \mathrm{d}$, respectively.

It was found in both this reproductive/developmental study and the additional developmental toxicity study that PO exposure of 1,000 ppm caused the intrauterine death of fetuses in pregnant female rats which had copulated with males also exposed to 1,000 ppm PO, throughout the 5- to 6-wk period including GD 0 through 19, whereas neither fetal death nor teratogenicity was elicited by the 2-wk inhalation exposure of pregnant females to the same level of PO during only the gestation period of GD 6 through 19, corresponding to the postimplantation period. Intrauterine deaths might be causally related to the additional PO exposure of the parents during the 2-wk premating period and of pregnant females during the early gestation period of GD 0 through 5, corresponding to the preimplantation period. Therefore, intrauterine deaths might be attributable to severe maternal toxicity, since exposure to $1,000 \mathrm{ppm}$ PO caused the death of three pregnant females. It might also be inferred that PO affected the oocytes and ovulation before fertilization, and the fertilized eggs and early embryos during the preimplantation period of gestation, in addition to the sperm before copulation as discussed in the preceding paragraph. Further study will be needed to look into the causative factors and mechanisms of this adverse effect. The adverse fetal effects of reduced body weights and decreased numbers of ossified sacral-caudal vertebrae found in the additional developmental toxicity study can be interpreted as being causally related to maternal systemic toxicity which was indicated by significantly reduced maternal body weights.

The present findings of reproductive/developmental toxicity are in contrast with those by Hardin et al. ${ }^{14)}$ who reported decreases in numbers of live fetuses and fetal body weights, skeletal alterations, decreased numbers of corpora lutea and implantations and decreased maternal body weight after inhalation exposure of female rats to 500 ppm PO for 3-wk before mating and for GD 1 through 16. On the contrary, we observed no reduction in the numbers of corpora lutea, no decrease in fetal body weight and no decrease in maternal body weights in the pregnant females exposed to $500 \mathrm{ppm}$ PO. Judging from the decreased maternal body weight, the difference in results might be attributable to severer maternal toxicity resulting from the longer duration of exposure of non-pregnant females to $500 \mathrm{ppm}$ PO before mating in the study of Hardin et al. However, our findings are in essential agreement with the results of two other studies. Harris et $a l .{ }^{15)}$ reported no evidence of external, skeletal or visceral malformations or variations, except for a sole variation of a rib of variable length on the seventh cervical vertebra in fetuses from rat dams exposed by inhalation to PO at levels up to $500 \mathrm{ppm}$ for $6 \mathrm{~h} / \mathrm{d}$ from GD 6 through 15. Hayes et al. ${ }^{16)}$ reported that no adverse effects on reproductive function over two generations were evidenced by inhalation exposure of male and female rats to PO at levels up to $300 \mathrm{ppm}$ for 14-wk before mating, and during the mating, gestation and lactation periods, and subsequent inhalation exposure of selected male and female $F_{1}$ pups to the same levels of PO for 17-wk beginning from 5 weeks of age until mating to produce the $\mathrm{F}_{2}$ litters.

In this study, the most sensitive lesion of PO-induced toxicity was found to occur in the nasal mucosa. The 
nasal lesion was confined to atrophy of the olfactory epithelium at the dorsal meatus in male rats exposed to $250 \mathrm{ppm}$, but the lesion extended to the entire area of the upper and lower respiratory tract in both sexes, including the nasal cavity, larynx and lung, when the inhalation exposure concentration was increased to $1,000 \mathrm{ppm}$. High susceptibility of the olfactory epithelium to inhaled PO insult might be causally related to a difference in activities of xenobiotic-metabolizing, detoxifying enzymes between the olfactory and respiratory mucosa, because two pathways for PO metabolism, hydrolysis to 1,2propanediol by epoxide hydrolase and conjugation with glutathione by glutathione S-transferase, were suggested $^{32)}$, and because the highest levels of epoxide hydrolase and glutathione $\mathrm{S}$-transferase $\mathrm{C}$ were found in the respiratory regions of nasal mucosa ${ }^{33)}$. The POinduced nasal lesion found in the present study is consistent with the findings of Eldridge et al. ${ }^{7)}$ that inhalation exposure of male rats to $\mathrm{PO}$ at levels up to $525 \mathrm{ppm}$ for $6 \mathrm{~h} / \mathrm{d}, 5 \mathrm{~d} / \mathrm{wk}$ for 4-wk induced degeneration of the olfactory epithelium and hyperplasia of the respiratory epithelium. They also found increased cell proliferation in both the respiratory and olfactory epithelia, as determined by bromodeoxyuridine incorporation into replicating epithelial cells, and established a No-Observed-Adverse-Effect-Level (NOAEL) of 50 ppm PO for the endpoints of both nasal histopathology and cell proliferation in the nasal mucosal tissue $^{7}$.

PO-induced injury of the olfactory mucosa found in the present study was characterized by the decreased number of olfactory sensory cells and the atrophy of both the nerve bundles and the olfactory glands, suggesting possible olfactory deficits in the PO-exposed rats that could possibly be extrapolated to workers exposed to PO. However, no human data pertinent to the PO-induced impairment of olfactory sensation is available, except for two reports that excessive exposure of workers to PO vapor may cause irritation of the eyes, respiratory tract and lungs ${ }^{5)}$, and the human odor detection threshold was 200 ppm for PO, a respiratory irritant ${ }^{34)}$. Inhalation exposure to hydrogen sulfide, a similar respiratory irritant, has been reported to cause the olfactory deficits and loss of olfactory sensation in exposed humans ${ }^{35,36)}$ and to induce the necrosis and regeneration of the olfactory mucosa and inhibition of nasal cytochrome oxidase in male $\mathrm{CD}$ rats ${ }^{37)}$. It is, therefore, inferred that the olfactory epithelial atrophy found in the present study reflects biologically significant adversity allowing extrapolation of animal toxicity data to human health effects. Therefore, the NOAEL was determined to be 125 ppm for the nasal endpoint in this study, because olfactory epithelial atrophy was found to occur at $250 \mathrm{ppm}$ and above. The present NOAEL value is comparable with the NOAEL of $50 \mathrm{ppm}$ for the same nasal endpoint reported by Eldridge et al. ${ }^{7}$. Harris et al. ${ }^{15)}$ reported that the NOAEL of PO for the endpoints of both increased cervical rib variation in rat fetuses and reductions in the maternal body weight gain and food consumption was $300 \mathrm{ppm}$. Therefore, the most sensitive sign of upper respiratory tract lesion would be manifested at a lower exposure level than any sign of the developmental, reproductive and systemic toxicities of PO.

It is interesting to note that the establishment of $2 \mathrm{ppm}$ TLV-TWA for PO by ACGIH was based on the NOAEL of $50 \mathrm{ppm}$ for the proliferative changes in nasal mucosa of rats ${ }^{17)}$, expecting that exposures below the TLV-TWA of $2 \mathrm{ppm}$ would not result in a sustained increase in cell proliferation, thus reducing the carcinogenic risk. However, it remains unresolved as to whether the degeneration and regeneration of olfactory and respiratory epithelia in rats that occurred at $150 \mathrm{ppm}$ and above in the study of Eldridge et al. ${ }^{7)}$ and at $250 \mathrm{ppm}$ and above in the present study would ultimately lead to a marginal increase in incidences of papillary adenomas of the nasal turbinate, which was reported in male and female exposed to $400 \mathrm{ppm}$ as some evidence of PO carcinogenicity (not clear evidence) by a 2 -yr NTP study ${ }^{11)}$, when a carcinogenic hypothesis of the cytolethality and subsequent cell proliferation ${ }^{38)}$ was taken into consideration for these NOAELs of PO. Standing aside from the issue of carcinogenicity, sensory irritation is one of the most important determinants for establishing TLVs for chemical substances, because $40 \%$ of 414 ACGIHTLVs were based on avoidance of sensory irritation ${ }^{39)}$. The human odor detection threshold was reported to be $200 \mathrm{ppm}$ for $\mathrm{PO}^{34)}$, which is approximately the same level as the NOAEL of $125 \mathrm{ppm}$ for PO found in this study. Therefore, the present finding of the olfactory epithelial lesion as the most sensitive endpoint in the PO animal toxicity may provide novel information about the animal toxicity data for health-based setting of the OEL of PO with respect to possible impairment of sense of smell (dysosmia) resulting from occupational exposure to respiratory irritants including PO and hydrogen sulfide.

In conclusion, the $6 \mathrm{~h} / \mathrm{d}$ inhalation exposure of male and female rats to PO vapor at $1,000 \mathrm{ppm}$ and below during a 5- to 6-wk period seriously affected parental survival, the upper and lower respiratory tract, the male and female reproductive system, motor function, parental body weights and fetal survival and development. The developmental toxicity of fetal death was manifested at parentally toxic exposure levels above $500 \mathrm{ppm}$. Atrophy of the olfactory epithelium was the most sensitive sign of PO toxicity, appearing at $250 \mathrm{ppm}$ and above. The NOAEL was determined to be $125 \mathrm{ppm}$ PO for the nasal endpoint.

Acknowledgments: The present study was contracted and supported by the Ministry of Health, Labour and Welfare. The authors are deeply indebted to Dr. Hisayoshi 
Ohta, Professor of Kitasato University, Graduate School of Medical Sciences, School of Allied Health Sciences, Department of Environmental, Occupational Health and Toxicology for his encouragement and thoughtful discussion throughout the present study.

\section{References}

1) International Programme on Chemical Safety. Propylene oxide. Environmental Health Criteria No 56. Geneva: WHO, 1985.

2) National Toxicology Program. Propylene oxide. Report on Carcinogens, 11th ed., Carcinogen Profiles 2004. NC: Constella Group, Inc., 2004.

3) Chemical Products Handbook 14102. Propylene oxide. Tokyo: The Chemical Daily Co., 2002: 476-477 (in Japanese).

4) National Institute for Occupational Safety and Health. National Occupational Exposure Survey (1981-1983). Estimated Numbers of Employees Potentially Exposed to Specific Agents by Occupation. Cincinnati, $\mathrm{OH}$ : NIOSH, 1990.

5) Hine C, Rowe VK, White ER, Darmer KI Jr, Youngblood GT. Propylene oxide. In: Patty's Industrial Hygiene and Toxicology, 3rd rev. ed., Vol IIA. NY: John Wiley \& Sons, 1981: 2186-2191.

6) Ohnishi A, Yamamoto T, Murai Y, Hayashida Y, Hori $\mathrm{H}$ and Tanaka I: Propylene oxide causes centralperipheral distal axonopathy in rats. Arch Environ Health 43, 353-356 (1988)

7) Eldridge SR, Bogdanffy MS, Jokinen MP and Andrew LS: Effects of propylene oxide on nasal epithelial cell proliferation in F344 rats. Fundam Appl Toxicol 27, 25-32 (1995)

8) Lynch DW, Lewis TR, Moorman WJ, Burg JR, Groth DH, Khan A, Ackerman LJ and Cockrell BY: Carcinogenic and toxicologic effects of inhaled ethylene oxide and propylene oxide in F344 rats. Toxicol Appl Pharmacol 76, 69-84 (1984)

9) Renne RA, Giddens WE, Boorman GA, Kovatch R, Haseman JE and Clarke WJ: Nasal cavity neoplasia in $\mathrm{F} 344 / \mathrm{N}$ rats and $(\mathrm{C} 57 \mathrm{BL} / 6 \times \mathrm{C} 3 \mathrm{H}) \mathrm{F}_{1}$ mice inhaling propylene oxide for up to two years. J Natl Cancer Inst 77, 573-582 (1986)

10) Kuper CF, Reuzel PGJ, Feron VJ and Verschuuren H: Chronic inhalation toxicity and carcinogenicity study of propylene oxide in Wistar rats. Food Chem Toxicol 26, 159-167 (1988)

11) National Toxicology Program. Toxicology and Carcinogenesis Studies of Propylene Oxide in F344/N Rats and $\mathrm{B} 6 \mathrm{C} 3 \mathrm{~F}_{1}$ Mice (Inhalation Studies), NTP Technical Report Series No. 267. Research Triangle Park, NC: NTP, 1985.

12) Omura M, Tanaka A, Mori K, Hirata M, Zao M and Inoue N: Dose-dependent testicular toxicity of propylene oxide in rats induced by repeated intraperitoneal injections. Fukuoka Acta Med 85, 204 210 (1994)

13) Hardin BD, Schuler RL, McGinnis PM, Niemeier RW and Smith RJ: Evaluation of propylene oxide for mutagenic activity in 3 in vivo test systems. Mutat Res 117, 337-344 (1983)

14) Hardin BD, Niemeier RW, Sikov MR and Hackett PL: Reproductive-toxicologic assessment of the epoxides ethylene oxide, propylene oxide, butylene oxide, and styrene oxide. Scand J Work Environ Health 9, 94102 (1983)

15) Harris SB, Schardein JL, Ulrich CE and Ridlon SA: Inhalation developmental toxicity study of propylene oxide in Fischer 344 rats. Fundam Appl Toxicol 13, 323-331 (1989)

16) Hayes WC, Kirk HD, Gushow TS and Young JT: Effect of inhaled propylene oxide on reproductive parameters in Fischer 344 rats. Fundam Appl Toxicol 10, 82-88 (1988)

17) American Conference of Governmental Industrial Hygienists. Propylene oxide. Documentation of the TLVs and BELs with other worldwide occupational exposure values, 6th ed. Cincinnati, OH: ACGIH, 2001.

18) Organisation for Economic Co-operation and Development. OECD Guideline for Testing of Chemicals, Vol. 2. Guideline 422, Combined Repeated Dose Toxicity Study with the Reproduction/ Developmental Toxicity Screening Test. Paris: OECD, 1996.

19) Organisation for Economic Co-operation and Development. OECD Principles of Good Laboratory Practice. Series on Principles of Good Laboratory Practice and Compliance Monitoring No.1. ENV/MC/ CHEM (98) 17. Paris: OECD, 1998.

20) Institute of Laboratory Animal Resources. Guide for the Care and Use of Laboratory Animals. Washington, DC: National Academy Press, 1996.

21) Takeuchi T, Okuda H, Arito H, Nagano K, Yamamoto $S$ and Matsushima T: Developmental effects of inhalation exposure to 2-bromopropane in rats. Reprod Toxicol 18, 431-437 (2004)

22) Aiso $S$, Takeuchi $T$, Arito $H$, Nagano K, Yamamoto $S$ and Matsushima T: Carcinogenicity and chronic toxicity in mice and rats exposed by inhalation to paradichlorobenzene for two years. J Vet Med Sci 67, 1019 1029 (2005)

23) Okuda H, Takeuchi T, Senoh H, Arito H, Nagano K, Yamamoto S and Matsushima T: Developmental toxicity induced by inhalation exposure of pregnant rats to $N, N$-dimethylacetamide. J Occup Health 48 , 154-160 (2006)

24) Okuda H and Nagao T: Cardiovascular defects induced by prenatal exposure to phenobarbital in rats. Congenit Anom Kyoto 46, 97-104 (2006)

25) Renne RA, Dungworth DL, Keenan CM, Morgan KT, Hahn FF, Schwartz LW. Non-proliferative lesions of the respiratory tract in rats. In: Guides for Toxicologic Pathology. Washington, DC: STP/ARP/AFIP, 2003: 126.

26) Lawley PD and Jarman M: Alkylation by propylene oxide of deoxyribonucleic acid, adenine, guanosine and deoxyguanylic acid. Biochem J 126, 893-900 (1972)

27) Czene K, Osterman-Golkar S, Yun X, Li G, Zhao F, Perez HL, Li M, Natarajan AT and Segerback D: 
Analysis of DNA and hemoglobin adducts and sister chromatid exchanges in a human population occupationally exposed to propylene oxide: a pilot study. Cancer Epidemiol Biomarkers Prev 11, 315-318 (2002)

28) Sega GA and Owens JG: Binding of ethylene oxide in spermiogenic germ cell stages of the mouse after lowlevel inhalation exposure. Environ Mol Mutagenesis 10, 119-127 (1987)

29) Herbert DC, Supakar PC, Roy AK. Male reproduction. In: Witorsch RJ, ed. Reproductive Toxicology, 2nd ed. NY: Raven Press, 1995: 3-21.

30) Sundaram K, Witorsch RJ. Toxic effects on the testes. In: Witorsch RJ, ed. Reproductive Toxicology, 2nd ed. NY: Raven Press, 1995: 99-121.

31) Mauderly JL, Tesarek JE, Sifford LJ and Sifford LJ: Respiratory measurements of unsedated small laboratory mammals using nonrebreathing valves. Lab Anim Sci 29, 323-329 (1979)

32) Tachizawa H, MacDonald TL and Neal RA: Rat liver microsomal metabolism of propyl halides. Mol Pharmacol 22, 745-751 (1982)

33) Baron J, Burke JP, Guengerich FP, Jakoby WB and Voigt JM: Sites for xenobiotic activation and detoxication within the respiratory tract: implications for chemically induced toxicity. Toxicol Appl Pharmacol 93, 493-505 (1988)

34) Jacobson KH, Hackley EB and Feinsilver L: The toxicity of inhaled ethylene oxide and propylene oxide vapors. AMA Arch Ind Health 13, 237-244 (1956)

35) Hirsch AR and Zavala G: Long term effects on the olfactory system of exposure to hydrogen sulphide. Occup Environ Med 56, 284-287 (1999)

36) Tvedt B, Skyberg K, Aaserud O, Hobbesland $\AA$ and Mathiesen T: Brain damage caused by hydrogen sulfide: A follow-up study of six patients. Am J Ind Med 20, 91-101 (1991)

37) Brenneman KA, Meleason DF, Sar M, Marshall MW, James RA, Gross EA, Martin JT and Dorman DC: Olfactory mucosal necrosis in male CD rats following acute inhalation exposure to hydrogen sulfide: Reversibility and the possible role of regional metabolism. Toxicol Pathol 30, 200-208 (2002)

38) Butterworth BE: Consideration of both genotoxic and nongenotoxic mechanisms in predicting carcinogenic potential. Mutat Res 239, 117-132 (1990)

39) Paustenbach D: Approaches and considerations for setting occupational exposure limits for sensory irritants: Report of recent symposia. Am Ind Hyg Assoc J 62, 697-704 (2001) 